\title{
Prospective and dyadic associations between expectant parents' prenatal hormone changes and postpartum parenting outcomes
}

\author{
Robin S. Edelstein $^{1 *}$ | William J. Chopik ${ }^{2}$ | Darby E. Saxbe ${ }^{3}$ | \\ Britney M. Wardecker ${ }^{1}$ | Amy C. Moors ${ }^{4}$ | Onawa P. LaBelle
}

${ }^{1}$ Department of Psychology, University of Michigan, Ann Arbor, Michigan

2 Department of Psychology, Michigan State University, East Lansing, Michigan

${ }^{3}$ Department of Psychology, University of Southern California, Los Angeles, California

${ }^{4}$ National Center for Institutional Diversity and Department of Women's Studies, University of Michigan, Ann Arbor, Michigan

${ }^{*}$ Correspondence

Robin S. Edelstein, Department of Psychology, University of Michigan, 530 Church Street, Ann Arbor, MI 48109.

Email: redelste@umich.edu

Funding Information

This research was supported by the Institute for Research on Women and Gender at the University of Michigan, the Society for the Psychological Study of Social Issues and the National Science Foundation.

\begin{abstract}
During the transition to parenthood, both men and women experience hormone changes that are thought to promote parental care. Yet very few studies have explicitly tested the hypothesis that prenatal hormone changes are associated with postpartum parenting behavior. In a longitudinal study of 27 first-time expectant couples, we assessed whether prenatal hormone changes were moderated by self- and partner-reported parenting outcomes at 3 months postpartum. Expectant fathers showed prenatal declines in testosterone and estradiol, and larger declines in these hormones were associated with greater contributions to household and infant care tasks postpartum. Women whose partners showed larger testosterone declines also reported receiving more support and more help with household tasks. Expectant mothers showed prenatal increases in testosterone and estradiol, and larger increases in these hormones were associated with lower partner-rated support. Together, our findings provide some of the first evidence that prenatal hormone changes may indeed be functional and that the implications of these changes may be detectable by co-parents.
\end{abstract}

KEYWORDS

couples, estradiol, longitudinal, pregnancy, testosterone, transition to parenthood

\section{1 | INTRODUCTION}

The transition to first-time parenthood is a major life event for many couples. Although some couples adjust to parenthood relatively well, others have more difficulty adapting to their new roles as parents or to the ensuing disruptions in their romantic relationships. In fact, becoming a parent is considered one of the most stressful events a couple can experience (Luhmann, Hofmann, Eid, \& Lucas, 2012), and many people report declines in relationship satisfaction and increases in conflict after the birth of their first child (Doss, Rhoades, Stanley, \& Markman, 2009). These changes, in turn, can negatively impact parental behavior and children's adjustment (Buehler \& Gerard, 2002; Krishnakumar \& Buehler, 2000).

Why do some people adapt more easily to parenthood than others, and are there predictors of postpartum outcomes that can be identified even before people become parents? The goal of the current study was to examine a predictor of postpartum parenting outcomes that has been neglected in most research on the transition to parenthood: prenatal changes in steroid hormones associated with bonding and parental care. These changes are especially marked among expectant mothers, but recent research suggests that expectant fathers also show reliable changes in hormones, such as testosterone and estradiol, that are thought to support parental care (Edelstein et al., 2015; Gettler, McDade, Feranil, \& Kuzawa, 2011). Relatively little is known about the postpartum implications of prenatal hormone changes, particularly among fathers; however, there are reasons to expect that such changes may be functional, in that they may explain some of the variability in postpartum outcomes (Saltzman \& Ziegler, 2014).

In the current study, we investigated whether prenatal changes in first-time expectant parents' testosterone and estradiol levels 
predicted parenting outcomes at 3 months postpartum. We specifically examined both parents' postpartum perceptions of partner support and division of household and infant care tasks. We also examined dyadic associations between prenatal hormone changes and postpartum outcomes; that is, are changes in one parent's hormones associated with his or her partner's postpartum parenting outcomes? In the following sections, we describe what is currently known about testosterone and estradiol changes among expectant parents and the existing evidence for the utility of these changes with respect to parenting

\section{1 | Prenatal hormone changes in expectant parents}

\subsection{1 | Testosterone}

Testosterone is associated with both aggression and parental care (at higher vs. lower levels, respectively; van Anders, Goldey, \& Kuo, 2011; Wingfield, Hegner, Dufty, \& Ball, 1990). In women and other female mammals, testosterone increases during pregnancy (Edelstein et al., 2015; O'Leary, Boyne, Flett, Beilby, \& James, 1991) and then declines gradually from the prenatal to the postpartum period (Fleming, Ruble, Krieger, \& Wong, 1997). Prenatal increases in testosterone are thought to contribute to the maintenance of pregnancy and the initiation of parturition (Makieva, Saunders, \& Norman, 2014). Higher levels of maternal testosterone may also facilitate infant protection (Wynne-Edwards \& Reburn, 2000), although lower testosterone postpartum likely facilitates maternal behavior (e.g., Fite et al., 2005).

In men and other male mammals with extensive paternal care (e.g., Mongolian gerbils, California mice), testosterone appears to decline as a function of fatherhood (Reburn \& Wynne-Edwards, 1999; WynneEdwards, 2001). Cross-sectional studies indicate that human fathers generally have lower levels of testosterone compared to non-fathers (e.g., Gray, Yang, \& Pope, 2006), and there is limited longitudinal evidence to suggest that new fathers' testosterone declines pre- to post-birth (Berg \& Wynne-Edwards, 2001; Gettler et al., 2011). Our recent findings further suggest that these changes may begin even before men become fathers: In a longitudinal study of expectant parents, men's testosterone declined throughout the prenatal period, suggesting that the presence of an infant may not be necessary to initiate hormone changes (Edelstein et al., 2015). Although the specific mechanisms that drive changes in fathers' hormones are not yet entirely clear, such changes may reflect physical and/or psychological closeness to expectant mothers, anticipation about becoming a parent, or other life changes such as fluctuations in sleep quality or sexual activity (e.g., Genesoni \& Tallandini, 2009; Gettler, McDade, Agustin, Feranil, \& Kuzawa, 2013; Storey, Walsh, Quinton, \& Wynne-Edwards, 2000).

Post-birth declines in men's testosterone are thought to support paternal care by reducing aggression toward infants, focusing attention away from mating effort, and/or facilitating paternal attachment (Wynne-Edwards \& Reburn, 2000). For example, among Mongolian gerbils and marmosets, new fathers' testosterone is negatively associated with nurturant behavior, such as huddling, licking, and infant carrying (Clark \& Galef, 1999; Nunes, Fite, Patera, \& French, 2001). Human fathers with lower baseline testosterone levels also showed more affection and infant-directed vocalizations during a father-infant laboratory interaction task (Weisman, Zagoory-Sharon, \& Feldman, 2014). To our knowledge, there are no data linking changes in human fathers' testosterone prenatally with their parenting behavior postpartum. However, pre- to post-natal declines in testosterone are most pronounced among men who are more directly involved in infant care (Gettler et al., 2011), suggesting that these changes may be adaptive in helping men transition to their new role as fathers.

\subsection{2 | Estradiol}

Estradiol is associated with caregiving and bonding in humans and other mammals (Mileva-Seitz \& Fleming, 2011). Estradiol has also been linked with individual differences in desire for and responses to emotional closeness (Edelstein, Kean, \& Chopik, 2012, Edelstein, Stanton, Henderson, \& Sanders, 2010). In women and other female mammals, estradiol increases markedly during pregnancy (Edelstein et al., 2015), spikes just prior to birth, and drops precipitously thereafter (Fleming et al., 1997). Pre-birth increases in estradiol appear to be important for the onset of maternal behavior and for maternal attachment (Wynne-Edwards \& Reburn, 2000).

The role of estradiol in paternal behavior is much less clear, particularly among humans, and prior research yields potentially conflicting results (Saltzman \& Ziegler, 2014; Wardecker, Smith, Edelstein, \& Loving, 2015). For instance, in their longitudinal sample, Berg and Wynne-Edwards (2001) did not find evidence for prenatal changes in men's estradiol; however, there was an increase in the number of men with detectable estradiol levels in the weeks following delivery (but not in the subsample reported in Berg \& Wynne-Edwards, 2002). New fathers also had higher estradiol than a comparison sample of men without children (Berg \& Wynne-Edwards, 2001), suggesting that estradiol may increase as a function of fatherhood. These findings are consistent with evidence from other animals (e.g., California mice) suggesting that estradiol may facilitate paternal behavior (Trainor \& Marler, 2002). For instance, virgin male Mongolian gerbils treated with estradiol showed decreased aggression and enhanced paternal behavior toward pups (Martínez et al., 2015).

However, in our longitudinal study of expectant parents, human fathers showed declines in estradiol throughout the prenatal period (Edelstein et al., 2015); such findings may be consistent with research suggesting that estradiol can inhibit paternal behavior in some species. For instance, among male prairie voles, experimental manipulations that increase estradiol levels also increase aggression toward pups and decrease caregiving behavior (Cushing, Perry, Musatov, Ogawa, \& Papademetriou, 2008). Thus, it is possible that prenatal declines in estradiol inhibit aggression or other behaviors that may be incompatible with fatherhood. More generally, however, the very limited research to date provides reasons to expect both positive and negative associations between estradiol and parental behavior in mammalian fathers. The current study thus contributes much-needed data to this growing body of work. 


\section{2 | THE CURRENT STUDY}

In the current study, we examined prenatal changes in both couple members' testosterone and estradiol levels, and assessed whether these changes predicted new parents' perceptions of partner support and division of household and infant care tasks. Given that previous research links lower testosterone with more nurturant caregiving behavior, particularly among fathers, we expected that men who showed larger prenatal declines in testosterone would report the most constructive parenting behavior postpartum (e.g., greater involvement in household/infant care tasks). Expectant mothers show large prenatal increases in testosterone, and there is less evidence linking testosterone with maternal behavior; however, it is plausible that women who show smaller prenatal increases in testosterone might also report more constructive parenting behavior postpartum.

Estradiol, on the other hand, has been linked more consistently with maternal than paternal behavior. We therefore hypothesized that expectant mothers would report more constructive parenting postpartum to the extent that they showed larger prenatal increases in estradiol. Given that previous research points to both negative and positive associations between men's estradiol and caregiving behavior it is less clear how changes in estradiol might be linked with men's postpartum outcomes. Our analyses of fathers' prenatal hormones therefore allowed us to address previously inconsistent findings about the role of estradiol in paternal behavior.

Finally, we also assessed dyadic associations, that is, whether changes in one individual's hormone levels were associated with his or her partner's postpartum parenting outcomes. Very few studies on the neuroendocrinology of parenthood include both mothers and fathers, leaving major gaps in our understanding of the dyadic implications of hormone changes associated with parenthood. However, given the interdependence of couples, and new parents in particular, we expected that changes in one individual's hormone levels would also be associated with his or her partner's postpartum outcomes.

\section{3 | METHODS}

\section{1 | Overview of study design}

First-time expectant couples were invited to participate in a six-wave longitudinal study. The first four sessions were conducted prenatally (at approximately weeks 12, 20, 28, and 36 gestation) in our university laboratory. The second two sessions were conducted online at approximately 3- and 9-months postpartum, respectively. Salivary hormones were assessed during each of the four prenatal sessions; parenting-related outcomes were assessed at the two postpartum follow-up sessions.

\section{2 | Participants}

Participants were 58 individuals ( 29 couples) who were part of a larger study of neuroendocrine and psychological changes among first-time parents (see Edelstein et al., 2015, for additional details). Two couples did not complete the 3-month postpartum follow-up assessment, leaving 27 couples available for analysis in the current report. Couples were recruited via online and print advertisements and they received $\$ 25$ per session ( $\$ 50 /$ couple) for participating. To be eligible, both partners had to be between the ages of 18 and 45 (because of agerelated changes in hormones; Leifke et al., 2000), living together, expecting their first child, and within the first two trimesters of pregnancy. One male participant had a child from a previous relationship, but this was the first child together for all couples and the first pregnancy for all female participants. Smokers, people with medical conditions that could influence hormones (e.g., autoimmune disorders), and/or those taking hormone-altering medications (e.g., some psychiatric medications) were not eligible (see Schultheiss \& Stanton, 2009). Three additional couples began the study but are not included here because they: (1) were not in fact first-time parents; (2) terminated the pregnancy because of chromosomal abnormalities; or (3) did not respond to our requests to schedule subsequent sessions.

Women in the current sample ranged in age from 20 to 38 at the beginning of their participation $(M=29.19$ years, $S D=3.93)$; men ranged in age from 20 to $42(M=30.33$ years, $S D=4.50)$. Participants self-reported their race/ethnicity as $70 \%$ Caucasian, $4 \%$ Black or African American, 7\% Asian American, 6\% Hispanic, and 6\% mixed or other ethnicities ( $7 \%$ did not report their race/ethnicity). The majority of couples were married or engaged (91\%). Median household income was $\$ 50,000-\$ 75,000$ and $72 \%$ of participants had at least a college degree, suggesting that the families in our study (on average) resided in roughly middle to upper-middle class households (Pew Research Center, 2015).

\section{3 | Prenatal laboratory sessions}

All procedures were reviewed and approved by the University of Michigan Institutional Review Board. Prenatal laboratory sessions were scheduled, according to couples' due dates, at approximately 8week intervals (roughly weeks $12,20,28$, and 36 gestation). These intervals were modeled after those used by Fleming et al. (1997), who aimed to encompass each trimester and the very end of pregnancy (assessing women at 0-16 weeks, 20-27 weeks, 28-35 weeks, and 36-42 weeks); however, we began our study at 12 weeks (because of difficulty recruiting couples earlier in the first trimester) and targeted the beginning of the ranges used by Fleming for subsequent sessions. Couples were tested throughout the year, with initial sessions occurring between July 2011 and November 2012. Several couples began the study during the second trimester of pregnancy, and some did not complete the last session because their baby was born before their scheduled session, so there was some variability in the number of sessions completed by each couple ( $M=3.63$ sessions; $S D=.63$ ). Two couples completed two sessions, six couples completed three sessions, and 19 couples completed all four sessions.

Couple members came to the laboratory together for each session. Sessions were conducted on the same day of the week at the same time (as possible) for each couple to control for diurnal and dayto-day variations in hormone levels. Because hormone levels are most stable in the afternoon to evening hours (e.g., Schultheiss \& Stanton, 
2009), all couples were tested between $12: 30$ and 18:30 hr. Informed consent was obtained during the initial session and participants were told that they could withdraw from the study at any time without penalty. During each session, participants provided two saliva samples that were used to assess testosterone and estradiol levels, the first after a $20 \mathrm{~min}$ adaptation period and the second $20 \mathrm{~min}$ later, to increase measurement reliability. ${ }^{1}$ Participants also completed several questionnaires (e.g., of personality and psychological functioning) during each session that are not included in the current report.

\section{4 | Salivary testosterone and estradiol: collection and assessment}

Participants were asked to refrain from eating, drinking (except for water), smoking, or brushing their teeth for $1 \mathrm{hr}$ prior to the beginning of each session. After rinsing their mouths with water, participants used polypropylene tubes to provide two $7.5 \mathrm{ml}$ saliva samples during each of the in-lab sessions. Samples were frozen in our laboratory until further processing in the University of Michigan Core Assay Facility. Testosterone was assayed by radioimmunoassay (RIA), using commercially available kits from Siemens Medical Solutions Diagnostics (Los Angeles, CA); estradiol was assayed by enzyme-linked immunosorbent assay (ELISA), using commercially available kits from Salimetrics, Inc. (State College, PA).

For testosterone, the inter-assay coefficient of variation (CV) was $5.26 \%$ and $14.97 \%$ at high and low levels, respectively; the intra-assay $\mathrm{CV}$ was $9.86 \%$. Analytical sensitivity $\left(B_{0}-2 S D\right)$ for testosterone was $1.14 \mathrm{pg} / \mathrm{mL}$. The inter-assay CV for estradiol was $14.69 \%$ and $14.39 \%$ at high and low levels, respectively; the intra-assay CV was $4.60 \%$. Analytical sensitivity $\left(B_{0}-2 S D\right)$ for estradiol was $.10 \mathrm{pg} / \mathrm{ml}$.

Hormone values were averaged for each participant and session for both of the hormones; correlations between the two samples ranged from .94 to .97 . Average hormone values were inspected for outliers, separately by gender and session. To maximize the use of all available data, hormone values that were larger than three standard deviations above the mean for each gender and session were replaced with values corresponding to three standard deviations above the mean for that particular variable (i.e., Winsorized; Reifman \& Keyton, 2010; see also Edelstein et al., 2014, for a similar approach). Six values were replaced using this approach (1.2\% of the total 822 samples): two for testosterone (both male) and four for estradiol (two female, two male). Additionally, the distribution of estradiol values was positively skewed (skewness and kurtosis values >2.0), so log-transformed values were used in subsequent analyses. All results were virtually identical when estradiol values were log-transformed prior to winsorization of outliers.

\section{5 | Postpartum assessment}

An online postnatal follow-up questionnaire was sent to participants via email at 3 and 9 months after their scheduled due date $(M=14.36$ weeks; $S D=2.52$, for the first follow-up, and $M=40.87$ weeks; $S D=3.32$, for the second). Participants were asked to complete the questionnaires independently from their partner without consultation.
As is common in other studies of the transition to parenthood (e.g., Belsky \& Rovine, 1990), 3 months postpartum was chosen as the initial period of the follow-up because it falls within the most common time for the development of postpartum depression (Gavin et al., 2005) and the time when many parents return to work (which can increase stress; Feldman, Sussman, \& Zigler, 2004). Because our response rate was somewhat lower for the 9-month follow-up ( $n=24$ couples completed this follow-up) and because we expected prenatal effects to be strongest earlier during the postpartum period, only data from the 3 month follow-up are included in the current report. Preliminary analyses revealed that the majority of the effects reported here were consistent (albeit weaker in magnitude) with those obtained using the 9-month follow-up data. Data on fathers' postpartum relationship quality from the 3-month follow-up assessment are reported in Saxbe et al. (in press).

\subsection{1 | Perceived spousal support}

Perceived spousal support was assessed with the spousal support subscale of the Cleminshaw-Guidubaldi Parent Satisfaction Scale (Guidubaldi \& Cleminshaw, 1985). This 10-item measure reflects the participant's satisfaction with child rearing help provided by his or her spouse (e.g., "I am satisfied with the amount of time my spouse can give to our baby"; $\alpha=.96$ ). Participants rated their agreement with each statement on a scale ranging from 1 (strongly agree) to 4 (strongly disagree); scores were reversed for ease of interpretation such that higher scores reflect higher perceived support.

\subsection{2 | Division of household labor}

Division of household labor was assessed with a nine-item measure of household chores not including infant care (e.g., Cowan \& Cowan, 1987; Volling \& Belsky, 1992). Participants were asked to rate the extent to which they and their partner generally complete each task (e.g., household repairs, paying bills, grocery shopping; $\alpha=.55$ ), using a fivepoint scale ranging from 1 (always me) to 3 (both equally) to 5 (always partner). Lower scores reflect greater participation in household labor by the participant relative to the partner. The relatively low internal consistency of this measure in the current study likely reflects that most household responsibilities are typically divided between partners (such that endorsement of one particular task, such as cooking, might be negatively related to endorsement of another task, such as dishwashing). Thus, Cronbach's alpha should be interpreted accordingly for this and the division of infant care scale, as it may not be the most appropriate measure of reliability for divided tasks.

\subsubsection{Division of infant care}

Division of infant care was assessed using a nine-item Baby Care Checklist (Barnett \& Baruch, 1987). Participants were asked to rate whether they or their partner usually perform specific baby-related tasks (e.g., bathing baby, preparing baby's meals, changing wet diapers; $\alpha=.92$ ), using a five-point scale ranging from 1 (always me) to 3 (both equally) to 5 (always partner). Lower scores reflect greater participation in infant care by the participant relative to the partner. The high internal consistency of this measure likely reflects that one partner, typically the mother, is engaged in the majority of infant-related tasks. 


\subsection{Overview of statistical analyses}

For preliminary analyses, conducted using SPSS (version 22), mean differences were assessed with independent samples $t$-tests and associations were assessed with correlations. Because there were multiple measures of testosterone and estradiol nested within individuals, and individuals were nested within couples, our main analyses used multilevel modeling (Hierarchical Linear Modeling or HLM 7.0; Raudenbush, Bryk, Cheong, Congdon, \& du Toit, 2011). HLM is well-suited for nested data, such as repeated measures of hormones over time. This approach adjusts for statistical interdependencies that arise when repeated measures of the same construct are collected or when data are collected from couples, whose responses cannot be assumed to be independent. HLM also allows for the simultaneous calculation of both within-person (or within-couple) and betweenperson (or between-couple) effects when estimating changes over time. For instance, we can model both couples' initial hormone levels (i.e., intercept) and changes in these hormones over the course of pregnancy (i.e., slope) at Level 1 (the within-couple level) of our model. We can then test whether individual differences (e.g., when couples began the study) moderate both the intercept and slope at Level 2 of our model (the between-couple level). Importantly, HLM can also adjust for the fact that couples completed their prenatal visits at different weeks of pregnancy, and allows for inclusion of all participants when some data (e.g., some prenatal visits) are missing at the within-person level (Singer \& Willett, 2003).

A two-level model was used, including all available data from all couples. At Level 1 (the within-couple level), we included the Winsorized testosterone and Winsorized logged estradiol levels from each of the four prenatal visits as the outcome. We included the week of pregnancy that corresponded to each visit as a Level 1 predictor of changes in hormones over time (i.e., the slope). Pregnancy week was group-centered in SPSS before analyses so that the first week of couples' participation was coded as "0," allowing the intercept to reflect a meaningful value (i.e., an individual's hormone level at the beginning of their study participation). The intercept was modeled as a random effect and pregnancy week was modeled as a fixed effect.

Next, at Level 2 (the between-couple level), we included the week of the couples' first visit to the lab and the number of weeks elapsed between the first visit and the last visit as covariates. These covariates were included as predictors of the intercept of each model. Controlling for these variables allowed us to adjust not only for within-person change in hormone levels over pregnancy, but also between-couple differences in the timing of their participation in the study. Postpartum outcome data were included as predictors of the intercept and slope at Level 2 (see Quas, Yim, Edelstein, Cahill, \& Rush, 2011; Saxbe et al., 2015, for a similar statistical approach). Models were run separately for fathers' and mothers' hormones.

\section{4 | RESULTS}

\section{1 | Preliminary analyses}

Descriptive statistics for each hormone are presented in Table 1 by participant sex and session. These data are presented for broad descriptive purposes only; it is important to note that, given the variability in session timing, our analyses of change account for the exact week of measurement, rather than collapsing across testing session. The correlation between testosterone and estradiol levels at each time point tended to be positive for both men, $r$ 's range from - -15 to $.52(M=.27)$, and women, $r$ 's range from .21 to $.61(M=.38)$; however, only three out of eight of these correlations reached statistical significance, suggesting that hormone levels were only somewhat related within-person.

Means, standard deviations, and correlations among the postpartum measures are presented by sex in Table 2. There were sex differences in several of these measures, with mothers reporting that they performed a greater proportion of infant care, $t(52)=-8.90$, $S E=.13, p<.001, d=2.49$, but a smaller proportion of household tasks, $t(52)=4.68, S E=.13, p<.001, d=1.29$, compared to fathers. Mothers also reported receiving less support from their partners, $t$ $(52)=-2.97, S E=.18, p<.01, d=0.82$, compared to fathers. Within dyads (presented in bold in Table 2), division of household labor and infant care were negatively correlated, which would be expected given that these measures assess one's contribution relative to his or her partner (i.e., when one person reports more contributions, their partner is likely to report less). Also of note, mothers' perceptions of support were more closely tied to their perceptions of partner involvement in infant care than to their perceptions of partner involvement in household tasks; the opposite pattern emerged for fathers, with perceptions of support being more closely tied to assessments of the division of household labor than to infant care.

We additionally examined whether participants' hormone levels were related to infant sex or body mass index (BMI). Infant sex was not

TABLE 1 Descriptive statistics for hormones by sex and time point

\begin{tabular}{|c|c|c|c|c|}
\hline & Time $1(n=21) M(S D)$ & Time $2(n=25) M(S D)$ & Time $3(n=27) M(S D)$ & Time $4(n=25) M(S D)$ \\
\hline Week of pregnancy & $12.86(2.06)$ & $21.04(1.77)$ & $28.74(1.63)$ & $36.28(1.17)$ \\
\hline \multicolumn{5}{|l|}{ Fathers } \\
\hline Estradiol ( $\mu \mathrm{g} / \mathrm{dl})$ & $2.35(0.70)$ & $2.26(0.76)$ & $2.29(0.81)$ & $2.13(0.87)$ \\
\hline \multicolumn{5}{|l|}{ Mothers } \\
\hline Estradiol $(\mu \mathrm{g} / \mathrm{dl})$ & $6.77(2.70)$ & $20.33(8.99)$ & $35.88(14.81)$ & $80.96(42.84)$ \\
\hline
\end{tabular}


TABLE 2 Descriptive statistics and correlations among postpartum parenting variables

\begin{tabular}{|c|c|c|c|c|c|c|c|}
\hline & 1 & 2 & 3 & 4 & 5 & M & SD \\
\hline 1. Fathers' perceived support & & & & & & 3.73 & .58 \\
\hline 2. Fathers' reported division of household labor & $.64^{* *}$ & & & & & 2.54 & .48 \\
\hline 3. Fathers' reported division of infant care & .30 & .02 & & & & 3.47 & .44 \\
\hline 4. Mothers' perceived support & .15 & .02 & -.26 & & & 3.20 & .73 \\
\hline 5. Mothers' reported division of household labor & -.06 & $-.69^{* *}$ & .09 & .17 & & 3.14 & .47 \\
\hline 6. Mothers' reported division of infant care & -.26 & -.06 & $-.72^{* *}$ & $.59^{* *}$ & .24 & 2.32 & .50 \\
\hline
\end{tabular}

$N=27$ couples; bolded coefficients reflect within-dyad correlations on the same measure. ${ }^{* *} p<.01$.

significantly related to men's or women's testosterone or estradiol levels at any time point, all $p$ 's $>.11$, with the exception that women carrying female fetuses had lower estradiol levels at Time $2, t$ $(23)=-2.78, \quad p=.01 .^{2}$ Concurrent measures of BMI were also unrelated to participants' hormone levels, with the exception that men with a higher BMI had lower testosterone levels at the second time point only, $r(27)=-.38, p<.05$. Finally, we examined whether participants' age, the sex of the infant, and the timing of the postpartum assessment were associated with any our key measures. These variables were largely unrelated to our outcome measures or to prenatal hormone levels, with a few exceptions: Perceived spousal support was higher among participants with female, $M=3.71$; $S D=.40$, compared to male infants, $M=3.20 ; S D=.87, t(52)=2.79$, $S E=.18, p<.01, d=.78$. Infant sex was also a significant moderator of the association between testosterone changes and the division of infant care, so this variable was included in subsequent analyses involving infant care. In the interest of parsimony, we report all other analyses without additional covariates.

\section{2 | Multilevel modeling (HLM) results}

As described above, we used a two-level multilevel model to explore associations between prenatal hormones and postpartum outcomes. First, we tested a basic Level 1 (within-couple) model that included only participants' testosterone and estradiol as outcome variables predicted by the week of pregnancy. Consistent with our previously reported results (Edelstein et al., 2015), fathers showed significant prenatal declines (slope by pregnancy weeks) in both testosterone, $b=-.27, S E=.10, t=2.86, p=.005$, and estradiol levels, $b=-.01$, $S E=.0013, t=-2.00, p=.05$. Mothers showed significant prenatal increases in both testosterone, $b=1.78, S E=.19, t=9.22, p=.001$, and estradiol, $b=.10, S E=.004, t=22.50, p=.001$.

Next, at Level 2 (the between-couple level), we tested associations between hormone levels and changes over pregnancy and the 3month postpartum outcomes. To test these associations, we entered postpartum outcome variables as Level 2 moderators of the Level 1 intercept and slope of time elapsed across pregnancy (i.e., week of pregnancy at each of the four visits). First, we examined both partners' ratings of perceived spousal support. All results are shown in Table 3 , with fathers' hormones presented in the top panel and mothers' hormones presented in the bottom panel. Effects for testosterone are presented in the leftmost columns and effects for estradiol are presented in the rightmost columns. The coefficients of the analysis are presented in the "estimate" column and are analogous to regression coefficients; therefore, the coefficient for the intercepts can be interpreted as the initial or "starting value" of a particular hormone at the beginning of study participation. Estimates for the slopes reflect changes in hormones as a function of week, separately for fathers and mothers (as described in the basic Level 1 model above). The moderating influence of perceived social support is reported below each intercept and slope, and separate estimates are provided for participants' own ratings and for the ratings made by their partners.

As shown in the top left panel of Table 3, partner ratings of perceived support significantly moderated the slope of change in fathers' testosterone. That is, when fathers showed larger prenatal declines in testosterone, they were rated by their partners as providing more postpartum support. However, the slope of change in fathers' testosterone was not significantly moderated by their own perceptions of received support, $p>.10$. The same pattern appeared for mothers: As shown in the bottom left panel of Table 3, partner- but not self-ratings of perceived support significantly moderated the slope of change in mothers' testosterone. Mothers who showed smaller prenatal increases in testosterone received higher postpartum spousal support ratings from their partners, but mothers' testosterone changes were unrelated to their own perceptions of received support, $p>.10$.

Results for postpartum support as a function of changes in testosterone are illustrated in Figure 1; this figure, generated in HLM, shows estimated simple slopes at the $25 \%$ and $75 \%$ percentile for partner-rated spousal support, separately for fathers and mothers. As shown in the top panel of Figure 1, fathers who showed a larger decrease in testosterone across pregnancy were rated by their partners as being more supportive; as shown in the bottom panel of Figure 1, mothers who showed a smaller prenatal increase in testosterone were also rated by their partners as more supportive.

Associations between prenatal changes in estradiol and postpartum support are presented in the rightmost columns of Table 3. Similar to effects for testosterone, as shown in the top panel of Table 3, fathers' self-reports of postpartum support significantly moderated their own prenatal changes in estradiol. That is, fathers who showed smaller prenatal declines in estradiol reported receiving more postpartum support. As shown in the bottom panel of Table 3, mothers who showed smaller prenatal increases in estradiol were also rated by their partners as providing more postpartum support. 
TABLE 3 Multilevel model showing associations between prenatal hormones and postpartum spousal support; fixed effects with robust standard errors

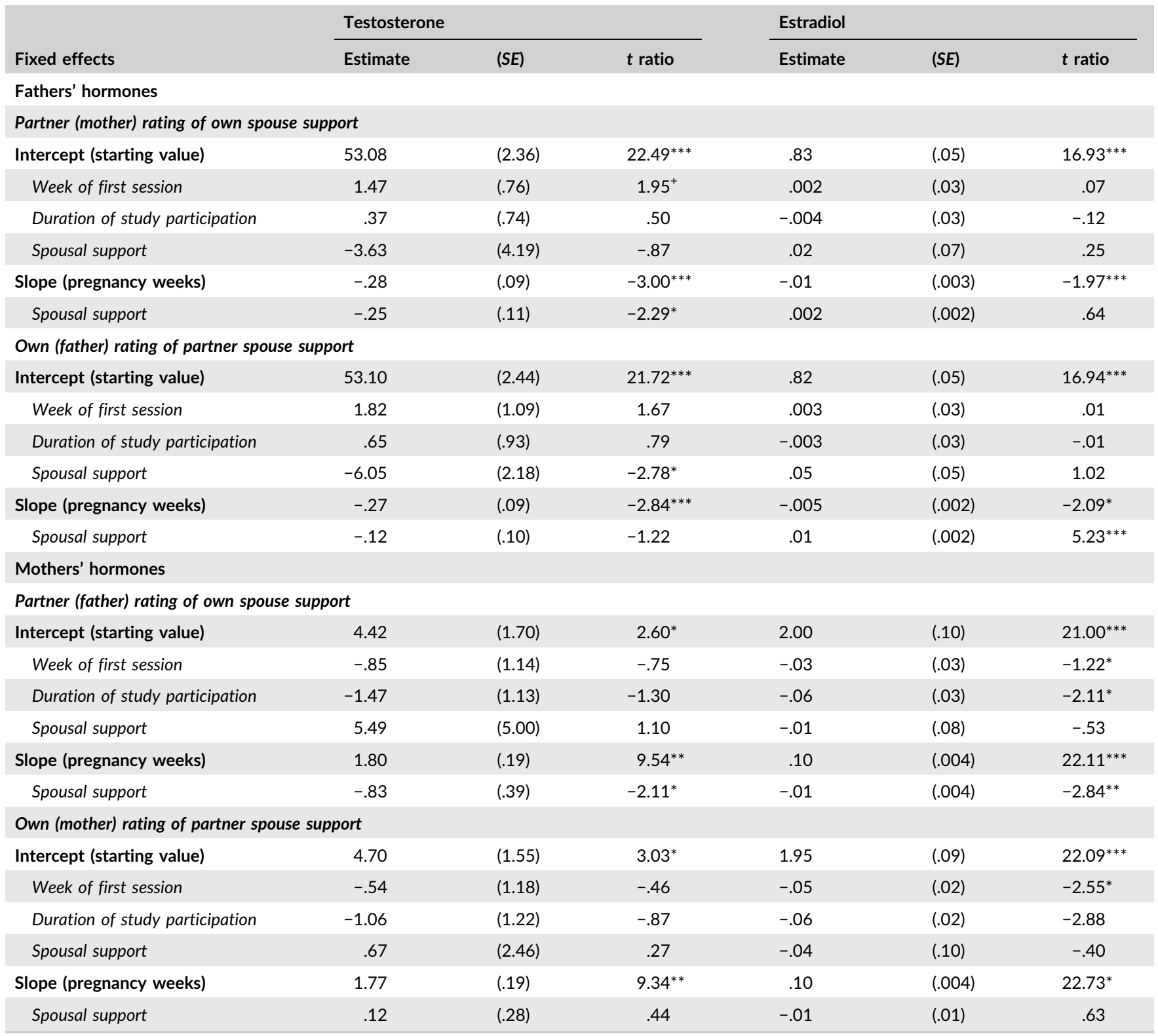

$N=27$ couples. Level 2 (between-couple) covariates are denoted by italics and placed below each bolded Level 1 effect. ${ }^{+} p<.10 ;{ }^{*} p<.05 ;{ }^{* *} p<.01 ;{ }^{* * *} p<.001$.

Next, we examined one's own and his or her partner's rating of postpartum division of household labor. Only men's hormones were significantly associated with the couples' division of labor, so Table 4 includes only results for fathers. As shown in the top panel of Table 4, partner ratings of division of labor significantly moderated the slope of fathers' testosterone changes. That is, men whose testosterone levels showed larger prenatal declines were rated by their partners as doing more household labor postpartum. Fathers' own ratings of the division of labor did not moderate their slope of testosterone change, $p>.10$ (not shown). Similarly, as shown in the bottom panel of Table 4, fathers' reports of division of labor significantly moderated the slope of their own estradiol changes. That is, men who showed larger estradiol declines across pregnancy reported doing more household labor postpartum. Men's prenatal estradiol changes were not associated with mothers' division of labor ratings, $p>.10$ (not shown). Further, women's prenatal testosterone and estradiol were not associated with their own or their partner's reports of division of labor, $p>.10$. Results for mothers' division of labor are provided in the top panel of Supplementary Table S1.

Next, we examined both partner's ratings of the division of infant care, with the significant results of our analyses shown in Table 5. As shown in the top panel of Table 5, partner reports of the division of infant care significantly moderated the slope of fathers' estradiol changes. That is, mothers reported that fathers provided more infant care when they showed smaller prenatal declines in estradiol. Consistent with these partner reports, and as shown in the bottom panel of Table 5, fathers' self-reports of the division of infant care significantly moderated the slope of their changes in estradiol. That is, fathers who showed larger prenatal declines in estradiol self-reported 


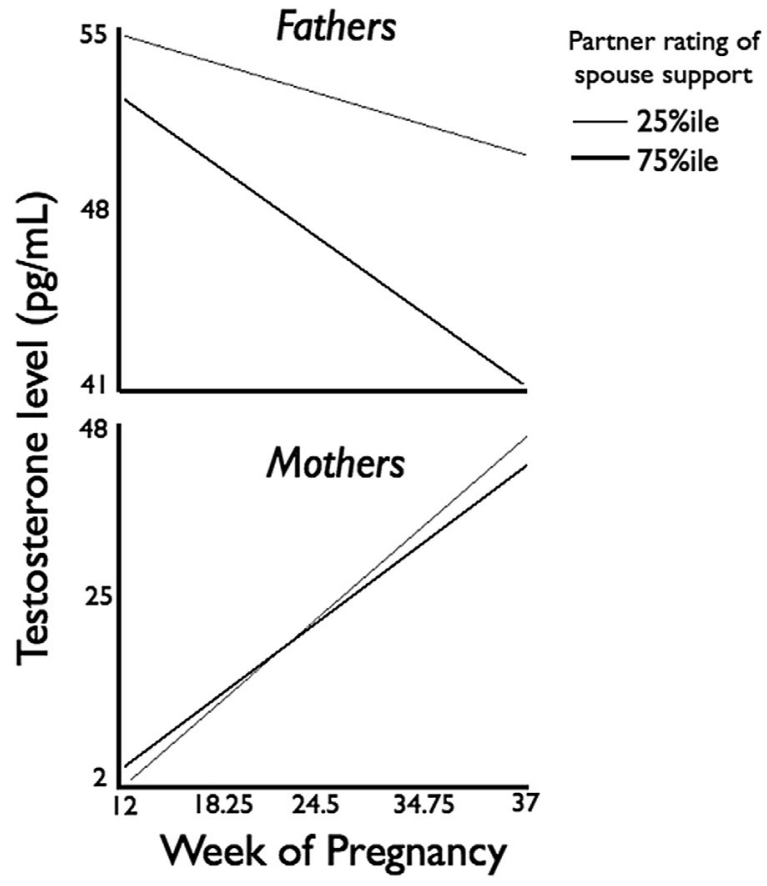

FIGURE 1 Associations between parents' testosterone levels across pregnancy and postpartum partner ratings of spousal support. Slopes for partner spouse support ratings at the 25th and 75th percentile are shown; top panel shows fathers' testosterone across pregnancy, bottom panel shows mothers' testosterone across pregnancy

that they provided more infant care postpartum. Figure 2 shows estimated simple slopes at the $25 \%$ and $75 \%$ percentile for own- and partner-rated division of infant care as a function of fathers' changes in estradiol. As depicted in Figure 2, when fathers showed larger declines in estradiol across pregnancy, both they (top panel) and their partners (bottom panel) reported that fathers did more infant care.

For both men and women, prenatal testosterone changes were not associated with either self- or partner-ratings of infant care, $p>.10$ (not shown). Mothers' estradiol was not associated with their own or their partners' ratings of the division of infant care, $p>.10$. Results for mothers' division of infant care are presented in the bottom panel of Supplementary Table S1.

Additionally, previous research suggests that the sex of the infant might affect the division of infant care, with fathers tending to be more involved with male versus female infants (see Raley \& Bianchi, 2006). Thus, we also tested whether infant sex moderated associations for this outcome variable. As shown in Table 6, the slope of fathers' prenatal testosterone changes was significantly moderated by the interaction between fathers' reports of the division of infant care and infant sex (presented in the top panel) as well as the interaction between mothers' reports of the division of infant care and infant sex (presented in the bottom panel). In both cases, these results indicated that, consistent with previous research, fathers who showed larger prenatal declines in testosterone were more involved in infant care, but only for male infants. There were no significant infant sex-by-childcare interactions for fathers' estradiol or for either of mothers' hormones, $p>.10$ (not shown).
TABLE 4 Multilevel model showing associations between fathers' prenatal hormones and division of labor; fixed effects with robust standard errors

\begin{tabular}{|c|c|c|c|}
\hline \multirow{3}{*}{$\begin{array}{l}\text { Fixed effects } \\
\text { Intercept (starting value) }\end{array}$} & Estimate & (SE) & $t$ ratio \\
\hline & \multicolumn{3}{|c|}{ Father testosterone } \\
\hline & 53.11 & $(2.44)$ & $21.80^{* * *}$ \\
\hline \multicolumn{4}{|l|}{ Level 2 covariates $^{a}$} \\
\hline Week of first session & 1.98 & (1.09) & $1.82^{+}$ \\
\hline Duration of study participation & .88 & (.93) & .94 \\
\hline Division of labor (mother rating) & 4.59 & $(4.43)$ & 1.03 \\
\hline Slope (pregnancy weeks) & -.27 & (.09) & $-2.91^{* *}$ \\
\hline \multicolumn{4}{|l|}{ Level 2 covariates } \\
\hline \multirow[t]{2}{*}{ Division of labor (mother rating) } & -.43 & $(.21)$ & $-2.02^{*}$ \\
\hline & \multicolumn{3}{|c|}{ Father estradiol } \\
\hline Intercept (starting value) & .84 & (.05) & $17.43^{* * *}$ \\
\hline \multicolumn{4}{|l|}{ Level 2 covariates $^{a}$} \\
\hline Week of first session & -.02 & (.30) & -.06 \\
\hline Duration of study participation & -.01 & (.03) & -.31 \\
\hline Division of labor (father rating) & -.10 & (.13) & -.82 \\
\hline Slope (pregnancy weeks) & -.01 & $(.002)$ & $-2.31^{*}$ \\
\hline \multicolumn{4}{|l|}{ Level 2 covariates } \\
\hline Division of labor (father rating) & .01 & $(.005)$ & $2.01^{*}$ \\
\hline
\end{tabular}

$N=27$ couples.

a Level 2 covariates refer to effects tested on each of the bolded Level 1 indices.

${ }^{+} p<.10 ;{ }^{*} p<.05 ;{ }^{* *} p<.01 ;{ }^{* * *} p<.001$

\section{5 | DISCUSSION}

The goal of the current study was to examine links between expectant parents' prenatal hormone changes and self- and partner-reported postpartum parenting behavior. Both men and women experience changes in hormones, such as testosterone and estradiol, during the transition to parenthood (e.g., Berg \& Wynne-Edwards, 2001; Edelstein et al., 2015), and there are reasons to expect that these changes may be functional or adaptive in that they help prepare people to become parents (Wynne-Edwards \& Reburn, 2000). Yet very few studies have explicitly tested the hypothesis that prenatal hormone changes are, in fact, related to postpartum outcomes.

Findings from the current study provide some of the first support for the functional nature of prenatal hormone changes in both men and women. On average, men showed prenatal declines in testosterone and estradiol, and larger declines in these hormones were associated with more constructive parenting outcomes. Specifically, fathers who showed larger prenatal declines in testosterone reported greater engagement in infant care tasks (although exclusively with male infants) at three months postpartum. Perhaps more strikingly, their partners reported that they were more supportive and that they contributed more to the division of household labor. Fathers who showed larger prenatal declines in estradiol reported contributing more to both household labor and infant care tasks. Moreover, their partners confirmed their contributions to infant care and reported feeling more supported by them. Women showed prenatal increases in 
TABLE 5 Multilevel model showing associations between fathers' prenatal estradiol and couples' division of infant care; fixed effects with robust standard errors

\begin{tabular}{|c|c|c|c|}
\hline Fixed effects & \multicolumn{3}{|c|}{ Father estradiol } \\
\hline Intercept (starting value) & .80 & (.06) & $14.37^{* * *}$ \\
\hline Week of first session & -.02 & (.04) & -.70 \\
\hline Duration of study participation & -.02 & (.04) & .42 \\
\hline Slope (pregnancy weeks) & -.003 & $(.002)$ & -1.25 \\
\hline \multicolumn{4}{|l|}{ Level 2 covariates } \\
\hline Division of infant care (mother rating) & .01 & $(.005)$ & $-2.25^{*}$ \\
\hline Intercept (starting value) & .80 & (.06) & $14.27^{* * *}$ \\
\hline Division of infant care (father rating) & -.12 & (.14) & -.84 \\
\hline Slope (pregnancy weeks) & -.003 & $(.003)$ & -1.27 \\
\hline \multicolumn{4}{|l|}{ Level 2 covariates } \\
\hline Division of infant care (father rating) & .02 & (.01) & $3.00^{* *}$ \\
\hline
\end{tabular}

$N=27$ couples.

aLevel 2 covariates refer to effects tested on each of the bolded Level 1 indices.

${ }^{*} p<.05 ;{ }^{* *} p<.01 ;{ }^{* * *} p<.001$.

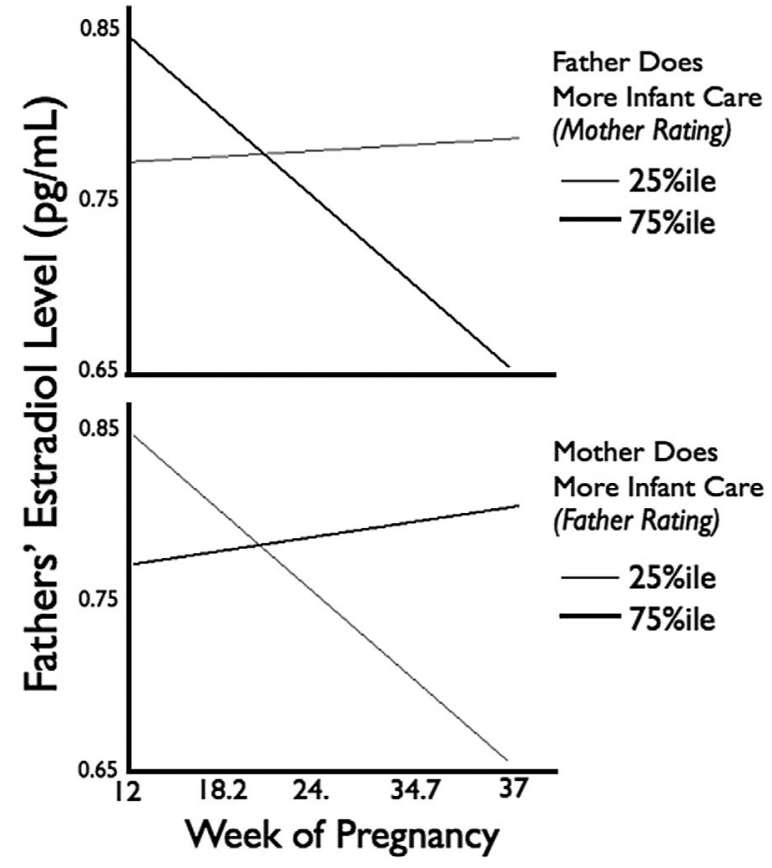

FIGURE 2 Associations between fathers' estradiol levels across pregnancy and postpartum ratings of division of infant care. Slopes for division of infant care ratings at the 25th and 75th percentile are shown; top panel shows results for mothers' rating of division of infant care, bottom panel shows results for fathers' rating of division of infant care testosterone and estradiol, and although there were fewer links between women's hormone changes and postpartum outcomes, mothers who showed smaller increases in either hormone were rated by their partners as providing more postpartum support.

Our findings are consistent with research documenting negative associations between testosterone and nurturant or caregiving behavior (Roney \& Gettler, 2015; van Anders et al., 2011). For instance, men with lower baseline testosterone levels report more parental investment (Mascaro, Hackett, \& Rilling, 2013) and greater empathy in response to infant cries (Fleming, Corter, Stallings, \& Steiner, 2002). Fewer relevant studies have included women, but in women lower testosterone has similarly been linked with more selfreported pro-social behavior and more positive feelings toward children (Deady, Smith, Sharp, \& Al-Dujaili, 2006; Harris, Rushton, Hampson, \& Jackson, 1996). The vast majority of previous work on this topic has been cross-sectional in nature, however, which makes it difficult to determine whether parents' testosterone levels causally predict, or instead are a consequence of, their parenting behavior. In the current study, participants' hormones were assessed prenatally, prior to any assessments of parenting or postpartum outcomes, which strengthens the case for a prospective link from testosterone changes to parenting behavior. Nevertheless, because we did not assess hormones postpartum, we cannot determine how postpartum behavior may have influenced parents' hormones during this period. In fact, the limited longitudinal research on changes in testosterone as a function of parenthood suggests that new fathers who are more engaged in childcare show larger postpartum declines in testosterone (Gettler et al., 2011). Thus, it is certainly possible that parents in our 
TABLE 6 Multilevel model showing associations between fathers' prenatal testosterone and couples' division of infant care, with interactions by infant sex; fixed effects with robust standard errors

\begin{tabular}{|c|c|c|c|}
\hline Fixed effects & \multicolumn{3}{|c|}{ Father testosterone } \\
\hline Intercept (starting value) & 53.70 & $(2.40)$ & $22.36^{* * *}$ \\
\hline Week of first session & 1.88 & $(1.12)$ & 1.69 \\
\hline Duration of study participation & .67 & (.98) & .69 \\
\hline Division of infant care (father rating) & .91 & (6.06) & .15 \\
\hline Interaction of infant sex and division of infant care (father rating) & 3.14 & $(2.22)$ & 1.41 \\
\hline Slope (pregnancy weeks) & -.31 & (.09) & $-3.52^{* *}$ \\
\hline \multicolumn{4}{|l|}{ Level 2 covariates } \\
\hline Intercept (starting value) & 53.22 & (2.39) & $22.28^{* * *}$ \\
\hline \multicolumn{4}{|l|}{ Level 2 covariates $^{\mathrm{a}}$} \\
\hline Week of first session & 1.30 & (.89) & 1.46 \\
\hline Duration of study participation & .19 & (.87) & .22 \\
\hline Infant sex & -2.17 & $(2.30)$ & -.95 \\
\hline Division of infant care (mother rating) & -3.40 & $(5.78)$ & -.59 \\
\hline Interaction of infant sex and division of infant care (mother rating) & .23 & $(2.50)$ & .09 \\
\hline Slope (pregnancy weeks) & -.29 & (.09) & $-3.14^{* *}$ \\
\hline \multicolumn{4}{|l|}{ Level 2 covariates } \\
\hline
\end{tabular}

$N=27$ couples.

aLevel 2 covariates refer to effects tested on each of the bolded Level 1 indices.

${ }^{* *} p<.01 ;{ }^{* * *} p<.001$.

study who performed more childcare tasks would similarly show lower levels of testosterone into the postpartum period.

Our findings also provide preliminary support for the hypothesis that lower levels of estradiol (i.e., larger declines in fathers and smaller increases in mothers) support parental behavior. Previous findings on this topic have been somewhat inconsistent, with some studies reporting facilitative effects of estradiol on parental behavior and others reporting inhibitory effects. For instance, experimental manipulations that increase estradiol also increase aggression toward infants in some male animals (e.g., prairie voles), but increase caregiving behavior in others (e.g., California mice; see Wardecker et al., 2015, for review). Similarly, in humans, estradiol has been positively linked with emotional closeness in both men and women (Edelstein et al., 2010, 2012), but also (in women) with dominance and sexual motivation (Roney \& Simmons, 2013; Stanton \& Edelstein, 2009). Taken together, these findings highlight the importance of context for understanding when and for whom estradiol may be associated with parental behavior. Perhaps prenatal changes that minimize estradiol levels also minimize aggressive, dominant, or sexual behaviors that would otherwise interfere with parenting. It is also important to note that, in men, estradiol is aromatized from circulating testosterone (Jones \& Lopez, 2014); thus, prenatal declines in men's estradiol levels may be attributable at least in part to concurrent declines in testosterone. Future research should examine how the hormone changes that we observed extend into the postpartum period and the extent to which these changes continue to influence (or are influenced by) parental behavior.

Our findings are noteworthy in that prenatal hormone changes were as often linked with partner-reported as they were with selfreported postpartum outcomes. In fact, changes in women's testosterone and estradiol were associated only with partner perceptions of received support. These findings suggest that the behaviors associated with prenatal hormone changes, such as contributions to household tasks, are detectable by co-parents and may influence postpartum outcomes. Insofar as perceptions about the equity of household labor are closely tied to relationship satisfaction during the transition to parenthood (e.g., Belsky, Lang, \& Huston, 1986), our findings further suggest that the hormone changes observed in the present study might serve to protect postpartum relationship quality. Moreover, previous research indicates that both 
men and women are more satisfied with and committed to their romantic relationships to the extent that their partners have lower levels of testosterone (Edelstein, van Anders, Chopik, Goldey, \& Wardecker, 2014); thus, declines in testosterone as a function of parenthood might help to maintain co-parent relationships. In fact, in our sample, men who showed prenatal declines in testosterone reported higher levels of postpartum relationship satisfaction, investment, and commitment (Saxbe et al., in press).

Perhaps surprisingly, women's prenatal hormones were less consistently related than men's hormones to their own or their partners' postpartum outcomes. Women's prenatal hormone changes are markedly larger than those in men, and they are more directly tied to fetal development and parturition, which could overwhelm any (relatively smaller) individual differences in postpartum outcomes. Moreover, although we measured a range of parenting-related outcomes, our measures may not have been sensitive or comprehensive enough to adequately assess women's experiences. Perhaps concerns about motherhood, breastfeeding, or work-life balance might be more closely related to women's hormones. Perinatal changes in women's estradiol have also been linked with postpartum depression (Bloch, Daly, \& Rubinow, 2003), which could certainly impact parenting and is worthy of attention in its own right.

It is also worth noting that we did not find any associations between parents' initial or average hormone levels and their postpartum outcomes, consistent with the idea that changes in hormones rather than average or baseline levels may be particularly relevant for behavioral outcomes (Carré, McCormick, \& Hariri, 2011; Endendijk et al., 2016). For instance, in one laboratory study, men reported greater concern in response to infant cries to the extent that they showed larger reductions in testosterone after listening to those cries; however, as in the current study, men's initial baseline testosterone levels were unrelated to their level of concern (Storey et al., 2000). Kuo and colleagues (2016) similarly found that fathers who showed larger testosterone declines while interacting with their infant during a stressful laboratory task were more positively engaged with their infants in a subsequent teaching task; again, initial (pre-task) testosterone levels were unrelated to fathers' behavior in the teaching task. Short-term changes in hormones as a function of a laboratory task likely reflect different processes than those that occur over longer periods of time during life transitions such as pregnancy; however, these findings highlight the importance of measuring not only baseline or initial hormone levels but also the extent to which hormones change over time, in both the short- and long-term, as a function of life experiences and contextual influences.

Our findings may also provide insight into why some individuals and couples fare better than others during the transition to first-time parenthood, as well as the biological mechanisms that might contribute to or reflect differences in postpartum outcomes. The vast majority of prior work on the transition to parenthood focuses on psychosocial predictors of adjustment and parenting outcomes, such as social support and relationship functioning (e.g., Doss et al., 2009; Stapleton et al., 2012). Our findings contribute to this work by suggesting an important role for the many physiological changes that occur during this major life transition in both expectant mothers and fathers. An important goal for future research will be to better understand the extent to which changes in hormones or other physiological processes might help to explain the effects of established risk and protective factors on postpartum outcomes.

Although we have argued that hormone changes shape behavior, it is also possible that people's prenatal beliefs about how they or their partners would behave with a young infant also influenced neuroendocrine processes, which in turn influenced subsequent behavior. Because we did not assess (for instance) people's perceptions of their partners' contributions to infant care prior to the arrival of that infant, we cannot assess the causal impact of such perceptions. We also cannot rule out the possibility that unmeasured pre-existing differences among parents (e.g., interest in babies, Zilioli et al., 2016) contributed both to prenatal hormone changes and to postpartum outcomes. People's early life experiences, such as parental separation, maltreatment, or adversity, can also influence hormone levels and hormone responses (e.g., Fries, Ziegler, Kurian, Jacoris, \& Pollak, 2005). For instance, girls who grow up in more stressful environments (e.g., with absent fathers, higher levels of conflict) may experience the onset of puberty and associated hormonal changes earlier than those in less stressful environments (e.g., Moffitt, Caspi, Belsky, \& Silva, 1992). Such experiences also likely influence later parenting (e.g., Roberts, O'Connor, Dunn, Golding, \& the ALSPAC Study Team, 2004) and could contribute to hormone-behavior associations like those observed here.

Moreover, because we did not assess new parents' hormones prior to conception or postnatally, we cannot determine whether and how people's hormones change throughout the entire transition to parenthood. It is also impossible to know, based on our data, whether these changes are entirely attributable to parenthood as opposed to long-term pair-bonding. Longitudinal research suggests that testosterone declines both as a function of pair-bonding and of parenthood in both men and women (Gettler et al., 2011; Kuzawa, Gettler, Huang, \& McDade, 2010). Thus, the hormone changes we observed could reflect the enduring influences of pair-boding, as opposed to impending parenthood per se. Hormone changes associated with parenthood may also be larger or occur more rapidly pre- to postpartum as opposed to prenatally. These possibilities could be investigated with larger-scale longitudinal studies, such as those conducted over several decades as people transition from single to partnered status and become first-time parents (Gettler et al., 2011).

It is also important to acknowledge that our sample may not generalize to the larger population of first-time parents, in that participants in our sample were fairly educated, primarily Caucasian, and relatively older than first-time parents (Martin, Hamilton, Osterman, Curtin, \& Mathews, 2013). All of the couples in our sample were also living together, and the vast majority were either married or engaged, which is not necessarily the case for many firsttime parents (Martin et al., 2013). Thus, although our sample characteristics are similar to those of previous studies of prenatal hormone changes (Berg \& Wynne-Edwards, 2001; Storey et al., 2000), our findings should be considered in light of the homogeneity of our sample, which may have limited individual differences in hormone levels as well as changes in hormones over time. The 
relatively small size of our sample may also have limited our ability to detect very small changes in hormones and inter-individual differences in change, as well our ability to examine additional demographic or lifestyle factors that might influence hormone change (e.g., ethnicity, physical activity, diet; Sowers, Beebe, McConnell, Randolph, \& Jannausch, 2001). Moreover, because we only assessed hormones at four time points, and not all participants completed all assessments, we were unable to model non-linear changes in hormones over time that would require more frequent measurements. Thus, our analytic approach was not powerful enough to detect nonlinear effects that might be expected if (for instance) expectant parents' hormones changed more rapidly at some points during pregnancy than others. Future research should examine expectant parents' hormone changes with more time points in larger, more diverse samples to better understand the generalizability and reliability of our findings. It would also be beneficial to assess a broader array of postpartum outcomes, such as mental health or relationship satisfaction, particularly in light of the fact that many of our postpartum measures were positively intercorrelated.

These limitations notwithstanding, our findings provide critical new information about the neuroendocrine precursors and correlates of parental behavior. Expectant fathers showed prenatal declines in testosterone and estradiol, and larger declines in these hormones predicted more self- and partner-reported contributions to household and infant care tasks postpartum. Women whose partners showed larger testosterone declines also reported receiving more support and more help with household tasks. Expectant mothers showed prenatal increases in testosterone and estradiol, and smaller increases in these hormones predicted greater partner-rated support. Together, these findings are consistent with the idea that hormone changes during the transition to parenthood may be functional in helping prepare people to become parents. Moreover, our findings demonstrate the utility of assessing hormones both dyadically and over time, as many effects emerged exclusively for partner-reported outcomes and for changes in hormones as opposed to average or initial levels. Although our findings must be considered in light of our relatively small and homogenous sample, we hope that they will stimulate further research in this area to better understand whether and how hormone-parenting links extend into the postpartum period, ideally using larger-scale longitudinal designs, larger and more diverse samples, and more comprehensive assessments of parenting behavior.

\section{ACKNOWLEDGMENTS}

Financial support for this study was provided by the Institute for Research on Women and Gender at the University of Michigan and the Society for the Psychological Study of Social Issues. William Chopik and Onawa LaBelle were supported by Graduate Research Fellowships from the National Science Foundation during data collection. Britney Wardecker is now in the College of Health and Human Development at the Pennsylvania State University. She is partially supported by National Institute on Aging Grant T32 AG049676 to The Pennsylvania State University. Amy Moors is now in the College of Engineering at Purdue University.

\section{ENDNOTES}

${ }^{1}$ We also measured cortisol and progesterone in this study; however, expectant fathers did not show significant changes in these two hormones (Edelstein et al., 2015), so we do not include them in the current report.

${ }^{2}$ Although these (largely null) findings may seem counterintuitive at first glance, unlike fetal hormone measures, women's circulating testosterone and estradiol as measured in saliva or blood do not typically differ by the sex of the fetus (e.g., Hines et al., 2002; O'Leary et al., 1991; Troisi et al., 2003; Voegtline, Costigan, Kivlighan, Henderson, \& DiPietro, 2013).

\section{REFERENCES}

Barnett, R. C., \& Baruch, G. K. (1987). Determinants of fathers' participation in family work. Journal of Marriage and the Family, 49, 29-40.

Belsky, J., Lang, M., \& Huston, T. L. (1986). Sex typing and division of labor as determinants of marital change across the transition to parenthood. Journal of Personality and Social Psychology, 50, 517-522.

Belsky, J., \& Rovine, M. (1990). Patterns of marital change across the transition to parenthood: Pregnancy to three years postpartum. Journal of Marriage and Family, 52, 5-19.

Berg, S. J., \& Wynne-Edwards, K. E. (2001). Changes in testosterone, cortisol, and estradiol levels in men becoming fathers. Mayo Clinic Proceedings, 76, 582-592.

Berg, S. J., \& Wynne-Edwards, K. E. (2002). Salivary hormone concentrations in mothers and fathers becoming parents are not correlated. Hormones and Behavior, 42, 424-436.

Bloch, M., Daly, R. C., \& Rubinow, D. R. (2003). Endocrine factors in the etiology of postpartum depression. Comprehensive Psychiatry, 44, 234-246.

Buehler, C., \& Gerard, J. M. (2002). Marital conflict, ineffective parenting, and children's and adolescents' maladjustment. Journal of Marriage and Family, 64, 78-92.

Carré, J. M., McCormick, C. M., \& Hariri, A. R. (2011). The social neuroendocrinology of human aggression. Psychoneuroendocrinology, 36, 935-944.

Clark, M. M., \& Galef, B. G., Jr. (1999). A testosterone-mediated trade-off between parental and sexual effort in male mongolian gerbils (Meriones unguiculatus). Journal of Comparative Psychology, 113, 388-395.

Cowan, C. P., \& Cowan, P. A., (1987). Men's involvement in parenthood: Identifying the antecedents and understanding the barriers. In P. W. Berman, \& F. A. Pedersen (Eds.), Men's transitions to parenthood: Longitudinal studies of early family experience (pp. 145-174). Hillsdale, NJ: Lawrence Erlbaum Associates, Inc.

Cushing, B. S., Perry, A., Musatov, S., Ogawa, S., \& Papademetriou, E. (2008). Estrogen receptors in the medial amygdala inhibit the expression of male prosocial behavior. The Journal of Neuroscience, 28, 10399-10403.

Deady, D., Smith, M., Sharp, M., \& Al-Dujaili, E. (2006). Maternal personality and reproductive ambition in women is associated with salivary testosterone levels. Biological Psychology, 71, 29-32.

Doss, B. D., Rhoades, G. K., Stanley, S. M., \& Markman, H. J. (2009). The effect of the transition to parenthood on relationship quality: An eightyear prospective study. Journal of Personality and Social Psychology, 96, 601-619.

Edelstein, R. S., Kean, E. L., \& Chopik, W. J. (2012). Women with an avoidant attachment style show attenuated estradiol responses to emotionally intimate stimuli. Hormones and Behavior, 61, 167-175.

Edelstein, R. S., Stanton, S. J., Henderson, M. M., \& Sanders, M. R. (2010). Endogenous estradiol levels are associated with attachment avoidance and implicit intimacy motivation. Hormones and Behavior, 57, 230-236. 
Edelstein, R. S., van Anders, S. M., Chopik, W. J., Goldey, K. L., \& Wardecker, B. M. (2014). Dyadic associations between testosterone and relationship quality in couples. Hormones and Behavior, 65, 401-407.

Edelstein, R. S., Wardecker, B. M., Chopik, W. J., Moors, A. C., Shipman, E. L., \& Lin, N. J. (2015). Prenatal hormones in first-time expectant parents: Longitudinal changes and within-couple correlations. American Journal of Human Biology, 27, 317-325.

Endendijk, J. J., Hallers-Haalboom, E. T., Groeneveld, M. G., van Berkel, S. R., van der Pol, L. D., Bakermans-Kranenburg, M. J., \& Mesman, J. (2016). Diurnal testosterone variability is differentially associated with parenting quality in mothers and fathers. Hormones and Behavior, 80 , 68-75.

Feldman, R., Sussman, A. L., \& Zigler, E. (2004). Parental leave and work adaptation at the transition to parenthood: Individual, marital, and social correlates. Journal of Applied Developmental Psychology, 25, 459-479.

Fite, J. E., French, J. A., Patera, K. J., Hopkins, E. C., Rukstalis, M., \& Ross, C. N. (2005). Elevated urinary testosterone excretion and decreased maternal caregiving effort in marmosets when conception occurs during the period of infant dependence. Hormones and Behavior, 47, 39-48.

Fleming, A. S., Corter, C., Stallings, J., \& Steiner, M. (2002). Testosterone and prolactin are associated with emotional responses to infant cries in new fathers. Hormones and Behavior, 42, 399-413.

Fleming, A. S., Ruble, D., Krieger, H., \& Wong, P. Y. (1997). Hormonal and experiential correlates of maternal responsiveness during pregnancy and the puerperium in human mothers. Hormones and Behavior, 31, 145-158.

Fries, A. B. W., Ziegler, T. E., Kurian, J. R., Jacoris, S., \& Pollak, S. D. (2005). Early experience in humans is associated with changes in neuropeptides critical for regulating social behavior. Proceedings of the National Academy of Sciences of the United States of America, 102, 17237-17240.

Gavin, N. I., Gaynes, B. N., Lohr, K. N., Meltzer-Brody, S., Gartlehner, G., \& Swinson, T. (2005). Perinatal depression: A systematic review of prevalence and incidence. Obstetrics and Gynecology, 106, 1071-1083.

Genesoni, L., \& Tallandini, M. A. (2009). Men's psychological transition to fatherhood: An analysis of the literature, 1989-2008. Birth, 36, 305-318.

Gettler, L. T., McDade, T. W., Agustin, S. S., Feranil, A. B., \& Kuzawa, C. W. (2013). Do testosterone declines during the transition to marriage and fatherhood relate to men's sexual behavior? Evidence from the Philippines. Hormones and Behavior, 64, 755-763.

Gettler, L. T., McDade, T. W., Feranil, A. B., \& Kuzawa, C. W. (2011). Longitudinal evidence that fatherhood decreases testosterone in human males. Proceedings of the National Academy of Sciences of the United States of America, 108, 16194-16199.

Gray, P. B., Yang, C.-F. J., \& Pope, H. G. (2006). Fathers have lower salivary testosterone levels than unmarried men and married non-fathers in Beijing, China. Proceedings of the Royal Society B: Biological Sciences, 273, 333-339.

Guidubaldi, J., \& Cleminshaw, H. K. (1985). The development of the cleminshaw-Guidubaldi parent satisfaction scale. Journal of Clinical Child Psychology, 14, 293-298.

Harris, J. A., Rushton, J. P., Hampson, E., \& Jackson, D. N. (1996). Salivary testosterone and self-report aggressive and pro-social personality characteristics in men and women. Aggressive Behavior, 22, 321-331.

Hines, M., Golombok, S., Rust, J., Johnston, K. J., \& Golding, J., \& the Avon Longitudinal Study of Parents and Children Study Team. (2002). Testosterone during pregnancy and gender role behavior of preschool children: A longitudinal, population study. Child Development, 73, 1678-1687.
Jones, R. E., \& Lopez, K. H. (2014). Human reproductive biology. London, UK: Academic Press.

Krishnakumar, A., \& Buehler, C. (2000). Interparental conflict and parenting behaviors: A meta-analytic review. Family Relations, 49, 25-44.

Kuo, P. X., Saini, E. K., Thomason, E., Schultheiss, O. C., Gonzalez, R., \& Volling, B. L. (2016). Individual variation in fathers' testosterone reactivity to infant distress predicts parenting behaviors with their 1-year-old infants. Developmental Psychobiology, 58, 303-314.

Kuzawa, C. W., Gettler, L. T., Huang, Y., \& McDade, T. W. (2010). Mothers have lower testosterone than non-mothers: Evidence from the Philippines. Hormones and Behavior, 57, 441-447.

Leifke, E., Gorenoi, V., Wichers, C., von zur Mühlen, A., von Büren, E., \& Brabant, G. (2000). Age-related changes of serum sex hormones, insulin-like growth factor, and sex-hormone binding globulin levels in men: Cross-sectional data from a healthy male cohort. Clinical Endocrinology, 53, 689-695.

Luhmann, M., Hofmann, W., Eid, M., \& Lucas, R. E. (2012). Subjective wellbeing and adaptation to life events: $A$ meta-analysis on differences between cognitive and affective well-being. Journal of Personality and Social Psychology, 102, 592-615.

Makieva, S., Saunders, P. T., \& Norman, J. E. (2014). Androgens in pregnancy: Roles in parturition. Human Reproduction Update, 20, 542-559.

Martin, J. A., Hamilton, B. E., Osterman, M. J. K., Curtin, S. C., \& Mathews, T. J. (2013). Births: Final data for 2012 National Vital Statistics Reports. Hyattsville, MD: National Center for Statistics.

Martínez, A., Ramos, G., Martínez-Torres, M., Nicolás, L., Carmona, A., \& Cárdenas, M., \& Luis, J. (2015). Paternal behavior in the Mongolian gerbil (Meriones unguiculatus): Estrogenic and androgenic regulation. Hormones and Behavior, 71, 91-95.

Mascaro, J. S., Hackett, P. D., \& Rilling, J. K. (2013). Testicular volume is inversely correlated with nurturing-related brain activity in human fathers. Proceedings of the National Academy of Sciences of the United States of America, 110, 15746-15751.

Mileva-Seitz, V., \& Fleming, A. S., (2011). How mothers are born: A psychobiological analysis of mothering. In A. Booth, S. M. McHale, \& N. S. Landale (Eds.), Biosocial foundations of family processes (pp. 3-34). New York, NY: Springer.

Moffitt, T. E., Caspi, A., Belsky, J., \& Silva, P. A. (1992). Childhood experience and the onset of menarche: $A$ test of a sociobiological model. Child Development, 63, 47-58.

Nunes, S., Fite, J. E., Patera, K. J., \& French, J. A. (2001). Interactions among paternal behavior, steroid hormones, and parental experience in male marmosets (Callithrix kuhlii). Hormones and Behavior, 39, 70-82.

O'Leary, P., Boyne, P., Flett, P., Beilby, J., \& James, I. (1991). Longitudinal assessment of changes in reproductive hormones during normal pregnancy. Clinical Chemistry, 37, 667-672.

Pew Research Center. (2015). The American middle class is losing ground: No longer the majority and falling behind financially. Washington, DC: Pew Research Center.

Quas, J. A., Yim, I. S., Edelstein, R. S., Cahill, L., \& Rush, E. B. (2011). The role of cortisol reactivity in children's and adults' memory of a prior stressful experience. Developmental Psychobiology, 53, 166-174.

Raley, S., \& Bianchi, S. (2006). Sons, daughters, and family processes: Does gender of children matter? Annual Review of Sociology, 32, 401-421.

Raudenbush, S., Bryk, A., Cheong, Y., Congdon, R., \& du Toit, M. (2011). HLM 7: Hierarchical Linear Nonlinear Modeling. Lincolnwood, IL: Scientific Software Interational, Inc.

Reburn, C. J., \& Wynne-Edwards, K. E. (1999). Hormonal changes in males of a naturally biparental and a uniparental mammal. Hormones and Behavior, 35, 163-176. 
Reifman, A., \& Keyton, K., (2010). Winsorize. In N. J. Salkind (Ed.), Encylopedia of research design (pp. 1636-1638). Thousand Oaks, CA: Sage.

Roberts, R., O'Connor, T., Dunn, J., Golding, J., \& the ALSPAC Study Team. (2004). The effects of child sexual abuse in later family life: Mental health, parenting and adjustment of offspring. Child Abuse \& Neglect, 28, 525-545.

Roney, J. R., \& Gettler, L. T. (2015). The role of testosterone in human romantic relationships. Current Opinion in Psychology, 1, 81-86.

Roney, J. R., \& Simmons, Z. L. (2013). Hormonal predictors of sexual motivation in natural menstrual cycles. Hormones and Behavior, 63, 636-645.

Saltzman, W., \& Ziegler, T. (2014). Functional significance of hormonal changes in mammalian fathers. Journal of Neuroendocrinology, 26, 685-696.

Saxbe, D. E., Adam, E. K., Schetter, C. D., Guardino, C. M., Simon, C., \& McKinney, C. O., \& Shalowtiz, M. U. (2015). Cortisol covariation within parents of young children: Moderation by relationship aggression. Psychoneuroendocrinology, 62, 121-128.

Saxbe, D. E., Edelstein, R. S., Lyden, H. M., Wardecker, B. M., Chopik, W. J., \& Moors, A. C. (in press). Fathers' decline in testosterone and synchrony with partner testosterone predicts greater postpartum relationship investment. Hormones and Behavior.

Schultheiss, O. C., Stanton, S. J., Harmon-Jones, E., \& Beer, J. S. (2009). Assessment of salivary hormones. In E. Harmon-Jones, \& J. S. Beer (Eds.) Methods in social neuroscience (pp. 17-44). New York, NY: Guilford Press.

Singer, J. D., \& Willett, J. B. (2003). Applied longitudinal data analysis: Modeling change and event occurrence. New York, NY: Oxford University Press.

Sowers, M., Beebe, J., McConnell, D., Randolph, J., \& Jannausch, M. (2001). Testosterone concentrations in women aged 25-50 years: Associations with lifestyle, body composition, and ovarian status. American Journal of Epidemiology, 153, 256-264.

Stanton, S. J., \& Edelstein, R. S. (2009). The physiology of women's power motive: Implicit power motivation is positively associated with estradiol levels in women. Journal of Research in Personality, 43, 1109-1113.

Stapleton, L. R. T., Schetter, C. D., Westling, E., Rini, C., Glynn, L. M., \& Hobel, C. J., \& Sandman, C. A. (2012). Perceived partner support in pregnancy predicts lower maternal and infant distress. Journal of Family Psychology, 26, 453.

Storey, A. E., Walsh, C. J., Quinton, R. L., \& Wynne-Edwards, K. E. (2000). Hormonal correlates of paternal responsiveness in new and expectant fathers. Evolution and Human Behavior, 21, 79-95.
Trainor, B. C., \& Marler, C. A. (2002). Testosterone promotes paternal behaviour in a monogamous mammal via conversion to oestrogen. Proceedings of the Royal Society B: Biological Sciences, 269, 823-829.

Troisi, R., Potischman, N., Roberts, J., Siiteri, P., Daftary, A., \& Sims, C., \& Hoover, R. N. (2003). Associations of maternal and umbilical cord hormone concentrations with maternal, gestational and neonatal factors (United States). Cancer Causes \& Control, 14, 347-355.

van Anders, S. M., Goldey, K. L., \& Kuo, P. X. (2011). The steroid/peptide theory of social bonds: Integrating testosterone and peptide responses for classifying social behavioral contexts. Psychoneuroendocrinology, 36, 1265-1275.

Voegtline, K., Costigan, K., Kivlighan, K., Henderson, J., \& DiPietro, J. (2013). Sex-specific associations of maternal prenatal testosterone levels with birth weight and weight gain in infancy. Journal of Developmental Origins of Health and Disease, 4, 280-284.

Volling, B. L., \& Belsky, J. (1992). Infant, father, and marital antecedents of infant-father attachment security in dual-earner and single-earner families. International Journal of Behavioral Development, 15, 83-100.

Wardecker, B. M., Smith, L. K., Edelstein, R. S., \& Loving, T. J. (2015). Intimate relationships then and now: How old hormonal processes are influenced by our modern psychology. Adaptive Human Behavior and Physiology, 1, 150-176.

Weisman, O., Zagoory-Sharon, O., \& Feldman, R. (2014). Oxytocin administration, salivary testosterone, and father-infant social behavior. Progress in Neuro-Psychopharmacology and Biological Psychiatry, 49, 47-52.

Wingfield, J. C., Hegner, R. E., Dufty, A. M., \& Ball, G. F. (1990). The "challenge hypothesis": Theoretical implications for patterns of testosterone secretion, mating systems, and breeding strategies. The American Naturalist, 136, 829-846.

Wynne-Edwards, K. E. (2001). Hormonal changes in mammalian fathers. Hormones and Behavior, 40, 139-145.

Wynne-Edwards, K. E., \& Reburn, C. J. (2000). Behavioral endocrinology of mammalian fatherhood. Trends in Ecology and Evolution, 15, 464-468.

Zilioli, S., Ponzi, D., Henry, A., Kubicki, K., Nickels, N., \& Wilson, M. C., \& Maestripieri, D. (2016). Interest in babies negatively predicts testosterone responses to sexual visual stimuli among heterosexual young men. Psychological Science, 27, 114-118.

\section{SUPPORTING INFORMATION}

Additional Supporting Information may be found online in the supporting information tab for this article. 